\title{
Comportamento do processo de têmpera no aço sae 1045 através do resfriamento em óleo com viscosidades distintas
}

Behavior of the hardening process in sae 1045 steel through cooling in oil with different viscosities

Comportamiento del proceso de témpera en el acero sae 1045 a través del enfriamiento en Aceite con viscosidades distintas

\author{
Revista Dissertar No30 V.1 ANO XIV \\ DOI: $10.24119 / 16760867$ ed114237 \\ Data de submissão: 15-08-2018 \\ Data de aceite: $30-10-2018$
}

por Renata Mercante Born ${ }^{1}$ e Christian Ferreira Mattos ${ }^{2}$

\begin{abstract}
Resumo
A taxa de transferência de calor durante o tratamento térmico pode modificar a microestrutura de um material. $\mathrm{O}$ meio de resfriamento é o principal objeto de estudo deste trabalho, pois ao proporcionar um melhor controle da transferência de calor espera-se que as tensões internas sejam reduzidas, se comparado com a água. $\mathrm{O}$ processo de têmpera e aquecimento dos aços está diretamente relacionado à densidade do fluxo de calor. Vários fatores influenciam no mecanismo de têmpera do metal processado. Entre esses fatores estão as condições internas à amostra que afetam a difusão de calor e a superfície da amostra e outras condições externas que podem afetar o potencial de extração de calor do fluído, como: agitação, pressão e temperatura de trabalho dos fluídos. A severidade do tratamento térmico se refere à habilidade do fluído na extração de calor do aço aquecido. Quanto maior a severidade do meio maior será a distorção da peça. A fim de analisar o impacto na microestrutura do aço SAE 1045 laminado a quente, o resfriamento foi realizado em dois tipos de óleo, com viscosidades diferentes, o resultado final foi comparado com a têmpera realizada através do resfriamento em água.
\end{abstract}

Palavras-chave: Têmpera. Resfriamento. Microestrutura.

1 Engenheira elétrica com ênfase em telecomunicações, mestre em engenharia Oceânica ênfase tecnologia submarina, especialista com MBA em inteligência empresários e gestão do conhecimento e professora universitária de graduação e pósgraduação da faculdade de engenharia da Universidade Estácio de Sá. e-mail: renata_ mercante@yahoo.com.br

2 Engenheiro mecânico da faculdade de engenharia da Unesa. e-mail: christianmattosfm@hotmail.com 
|Comportamento do processo de têmpera no aço sae 1045 através do resfriamento em óleo com viscosidades distintas

\section{Abstract}

The rate of heat transfer during treatment can modify the microstructure of a material. The way of cooling is the main object of the study of this work, because for the better control of the heat transference is expected the internal strains were reduced when compared with the water. The tempering process and heating the steels is directly related to the density of the heat flux. Several factors influence the quenching mechanism of the processed metal. These factors include the internal conditions to the sample that affect heat diffusion and the sample surface and other external conditions that may affect the heat extraction potential of the fluid, such as: stirring, pressure and working temperature of the fluids. The severity of the heat treatment refers to the ability to flow in the extraction of heat from the heated steel. The higher the severity of the ambient the greater the distortion of the part. In order to analyze the microstructure of SAE 1045 steel hot rolled, the cooling was done in two types of oil, with different viscosities, the final result was compared to the quenching done by cooling in water.

Keywords: Tempering. Cooling. Microstructure.

\section{Resumen}

La tasa de transferencia de calor durante el tratamiento térmico puede modificar la microestructura de un material. El medio de enfriamiento es el principal objeto de estudio de este trabajo, pues al proporcionar un mejor control de la transferencia de calor se espera que las tensiones internas sean reducidas, en comparación con el agua. El proceso de temple y calentamiento de los aceros está directamente relacionado con la densidad del flujo de calor. Varios factores influyen en el mecanismo de temple del metal procesado. Entre estos factores están las condiciones internas a la muestra que afectan la difusión de calor y la superficie de la muestra y otras condiciones externas que pueden afectar el potencial de extracción de calor del fluido, como: agitación, presión y temperatura de trabajo de los fluidos. La severidad del tratamiento térmico se refiere a la habilidad del fluido en la extracción de calor del acero calentado. Cuanto mayor sea la severidad del medio mayor será la distorsión de la pieza. A fin de analizar el impacto en la microestructura del acero SAE 1045 laminado en caliente, el enfriamiento se realizó en dos tipos de aceite, con viscosidades diferentes, el resultado final fue comparado con el temple realizado a través del enfriamiento en agua.

Palavras-chave: Têmpera. Resfriamento. Microestrutura.

\section{Introdução}

Ass propriedades mecânicas de um aço estão diretamente ligadas à sua microestrutura, que influencia na dureza, ductilidade, resistência mecânica e tenacidade. As diversas aplicações possíveis para um aço requerem diferentes combinações de características, que são possíveis 
de serem obtidas por meio de diversos tipos de tratamentos térmicos que alteram as propriedades do aço e dentre eles está o tratamento de têmpera. Tratamentos térmicos, como o de têmpera, são usados em larga escala para conseguir alcançar uma microestrutura mais consistente através da obtenção da martensíta (COLPAERT, 2008). Cada aplicação tem suas características distintas, de acordo com a taxa de transferência de calor entre a peça e o meio resfriamento pode-se conseguir estruturas diferenciadas. A martensíta, uma fase metaestável supersaturada de carbono, devido à sua transformação por cisalhamento, modifica o reticulado cristalino gerando tensões internas, portanto, na maioria das vezes após o tratamento de têmpera faz-se necassário a aplicação de um revenimento. $O$ revenimento é um aquecimento brando após a têmpera para aliviar as tensões do material. Os meios de resfriamento para a têmpera mais utilizados são água, óleo, salmoura e, recentemente, soluções poliméricas, cada um com características específicas e seu uso depende do resultado final desejado para a peça tratada (COLPAERT, 2008). No entanto, o objetivo deste trabalho é observar a microestrutura obtida após a têmpera utilizando para o resfriamento dois tipos de óleos com viscosidades diferentes e fazer uma comparação com o resfriamento em água. $\mathrm{O}$ presente trabalho foi dividido em quatro etapas a saber: etapa 1 que consiste na preparação do material; etapa 2 aplicação onde é realizada a da têmpera; etapa 3 em que é feita uma análise de dureza e microestrutura formada e por fim a etapa 4, na qual será feita a comparação dos resultados.

\section{Material e métodos}

Conforme o exposto para atingir este objetivo estabelecido lançar-se-á mão das seguintes ferramentas: Quatro corpos de prova de SAE 1045; bloco padrão de 62.5 HRC;

- Lixa d'água $(220,320,400,800,1200)$;

- Durômetro de bancada - Pantec;

- Forno elétrico tipo mufla;

- Água;

- Óleo SAE 5w30;

- Óleo lubrax SAE 20w50;

- Nital 2\%;

- Microscópio Pantec;

- Álcool;

- Algodão;

- Pasta de polir;

- Lubrificante composto de álcool e 1\% de glicerina;

- Politriz de metalografia;

- Cortadeira de amostra metalogáfica;

- Arco de serra; 
|Comportamento do processo de têmpera no aço sae 1045 através do resfriamento em óleo com viscosidades distintas

- Lixadeira de bancada;

- Base de vidro; Secador.

\section{Preparação do corpo de prova}

As amostras para o ensaio foram cortadas de uma barra de aço SAE 1045 com espessura de 15 mm e diâmetro de 22 mm, como mostra a figura 1 .

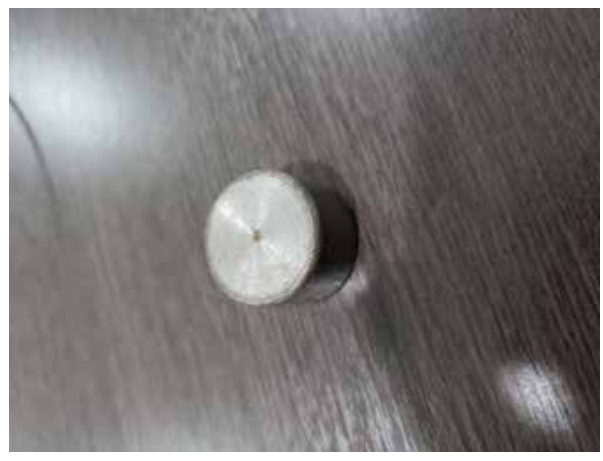

Figura 1: foto do corpo de prova

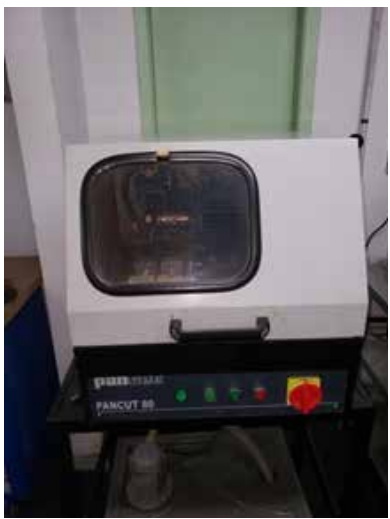

Figura 2: cortadeira de amostra metalográfica

Após o corte foi realizado o ensaio de dureza no durômetro de bancada da Pantec do aço SAE 1045 antes de ser feito qualquer alteração na microestrutura do material, conforme mostra a figura 4 . Entretanto, para verificar se o equipamento está realizando a leitura correta coloca-se um bloco-padrão em sua base/plataforma e observase visualmente o valor mostrado em seu visor. Essa verificação pode ser feita pelo proprietário ou operador, com o uso de blocos-padrão devidamente ajustados, para que uma possível diferença entre o valor mostrado e o bloco real seja detectada o quanto antes. Como mostra a figura 3. 


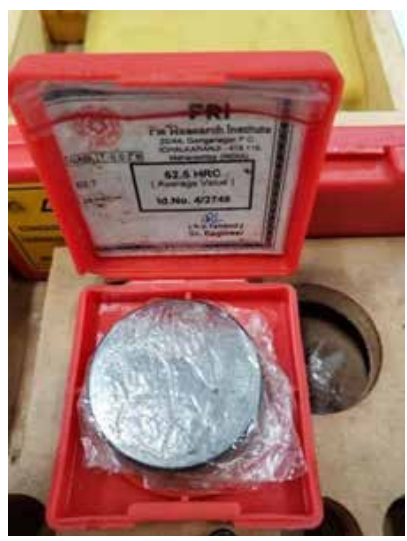

Figura 3: bloco padrão de 62.5 HRC para ferramenta de diamante

Após a verificação com o blocopadrão observou-se que a máquina estava apta para realizar as medições das durezas nas amostras.

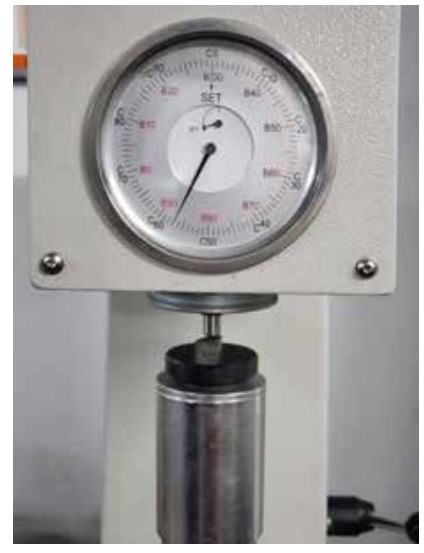

Figura 4: ensaio de dureza

A fim de obter um ensaio de dureza com valores mais precisos, o mesmo foi executado seis vezes em pontos diferentes do material. Segue os resultados na tabela 1 e sua respectiva média.

Tabela 1: dureza Aço SAE 1045, antes da têmpera

\begin{tabular}{|l|l|}
\hline Ensaio 1 & $84 \mathrm{HB}$ \\
\hline Ensaio 2 & $86 \mathrm{HB}$ \\
\hline
\end{tabular}


|Comportamento do processo de têmpera no aço sae 1045 através do resfriamento em óleo com viscosidades distintas

\begin{tabular}{|c|c|}
\hline Ensaio 3 & $82 \mathrm{HB}$ \\
\hline Ensaio 4 & $86 \mathrm{HB}$ \\
\hline Ensaio 5 & $87 \mathrm{HB}$ \\
\hline Ensaio 6 & $87 \mathrm{HB}$ \\
\hline Média dos valores & $85 \mathrm{HB}$ \\
\hline
\end{tabular}

A média do valor da dureza antes do tratamento foi de aproximadamente $85 \mathrm{HB}$. Após isto, foi feito um ensaio micrográfico do material para analisar a estrutura do aço antes do tratamento térmico, para tal, foram executados os seguintes procedimentos:

Procedimento 1 - A obtenção da superfície polida é iniciada sobre lixa, em direção normal aos riscos de lima ou de lixa grossa já existentes e é levado até o completo desaparecimento destes. Depois se passa para a lixa mais fina seguinte, mudando de $90^{\circ}$ a direção de polimento e continuando-o igualmente até terem desaparecidos os riscos de lixa anterior e assim por diante. O lixamento teve inicio com uma lixa de número 220, depois 320,400, 600 e por fim 800. Utilizando a lixadeira de bancada conforme a figura 5 .

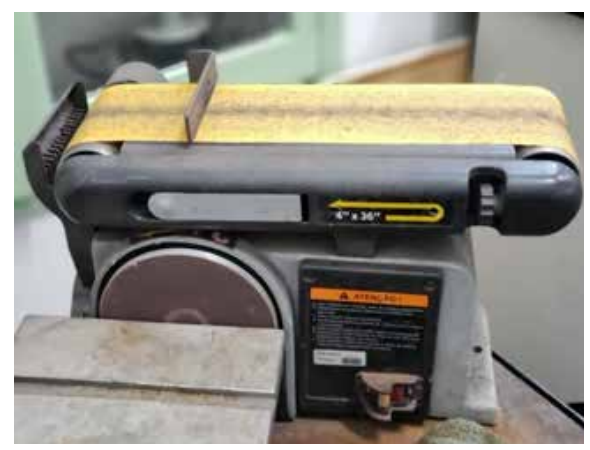

Figura 5: lixadeira de bancada

É preciso ter cuidados especiais para não arredondar as arestas do corpo de prova, pois poderá ocasionar uma divergência no momento da análise da microestrutura do material. É conveniente passar um pano sobre a superfície cada vez que se mudar de lixa, para não contaminar a nova com resíduos da anterior.

Logo após isto, a secção é cuidadosamente limpa com água, álcool 70\% e algodão.

Procedimento 2 - Utilizando a politriz Polipan 2 (figura 6) a área que foi anteriormente lixada é polida com pasta diamante 3 micron (figura 7) e lubrificante composto de álcool e 1\% de glicerina. 


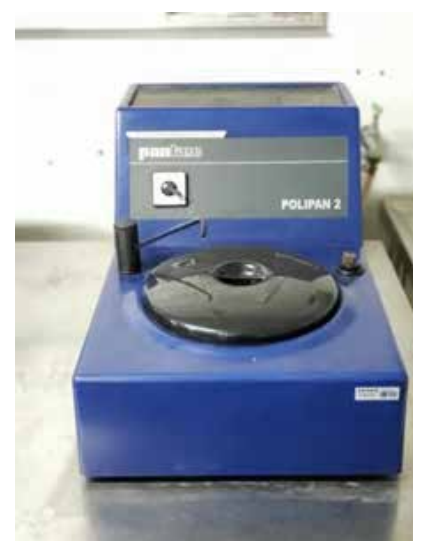

Figura 6: politriz Polipan 2

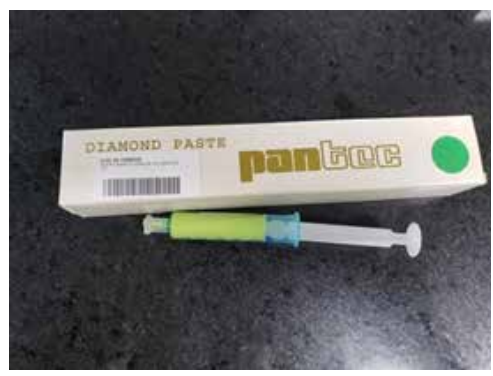

Figura 7: pasta diamante

Finalmente após todo o processo de polimento a amostra é limpa novamente com água, álcool, algodão e secada com a ajuda de um secador realizando movimentos circulares, podemos observar a amostra pronta na figura 8 .

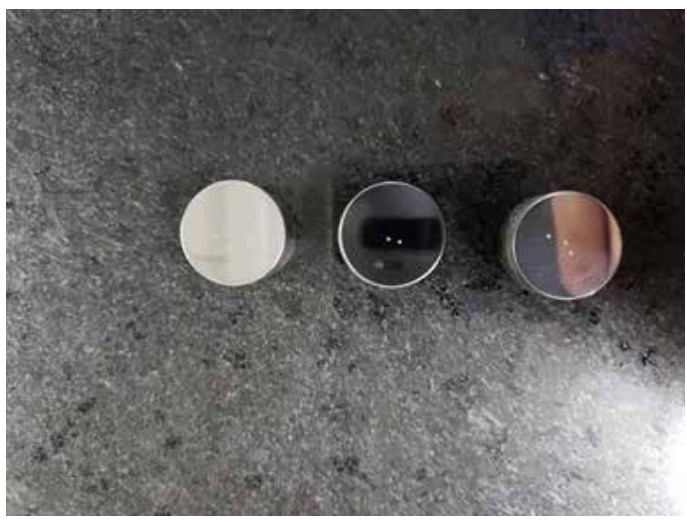

Figura 8: amostras polidas 
|Comportamento do processo de têmpera no aço sae 1045 através do resfriamento em óleo com viscosidades distintas

Procedimento 3 - Ataque pode ser feito de várias maneiras como mostra a tabela 2 (COLPAERTE, 1959), entretanto, o reagente utilizado para este estudo foi à solução de ácido nítrico a $2 \%$ em álcool etílico, denominada Nital, conforme a figura 9.

Tabela 2: tipos de ataques

\begin{tabular}{|l|l|}
\hline $\begin{array}{l}\text { Solução de ácido nítrico a 2\% em } \\
\text { álcool etílico. Nital. }\end{array}$ & $\begin{array}{l}\text { Pode ser empregada para todos } \\
\text { os aços siderúrgicos comuns. Não } \\
\text { ataca a ferrita nem a cementita, mas } \\
\text { delinea os seus contornos e colore de } \\
\text { escuro a perlita. }\end{array}$ \\
\hline $\begin{array}{l}\text { Solução de ácido pícrico a } 4 \% \text { em } \\
\text { álcool etílico. Picral. }\end{array}$ & Mesmas indicações que a anterior. \\
\hline $\begin{array}{l}\text { Solução de picrato de sódio. } 100 \mathrm{~g} \text { de } \\
\text { água destilada, } 25 \text { g de soda a } 36^{\circ} \mathrm{C} \\
\text { de baumé e } 2 \mathrm{~g} \text { de ácido pícrico. }\end{array}$ & $\begin{array}{l}\text { Este reativo colore a cementita, os } \\
\text { carbonetos complexos dos açosliga e } \\
\text { a steadita dos ferros fundidos. }\end{array}$ \\
\hline Ataque oxidante por aquecimento. & $\begin{array}{l}\text { Consiste em aquecer o corpo de } \\
\text { prova polido, mais ou menos de 250 } \\
\text { a 300C em presença do ar. Sobre a } \\
\text { superfície dos corpos forma-se uma } \\
\text { película finíssima de óxido. Este } \\
\text { modo de atacar é indicado se quer } \\
\text { mostrar a diferença de granulação } \\
\text { em certas regiões. }\end{array}$ \\
\hline
\end{tabular}

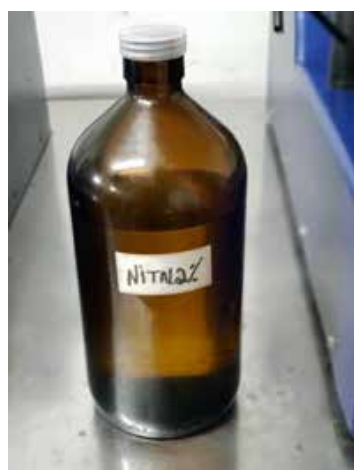

Figura 9: Nital 2\%

Procedimento 4 - Visualizar a microestrutura do material atacado com o auxílio do microscópio Pantec (figura 10). 


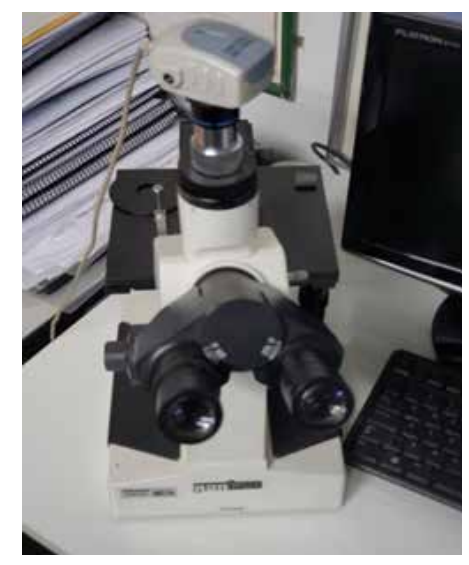

Figura 10: microscópio Pantec

Podemos então, observar a microestrutura do aço SAE 1045 antes do tratamento de têmpera ser realizado na figura 11.

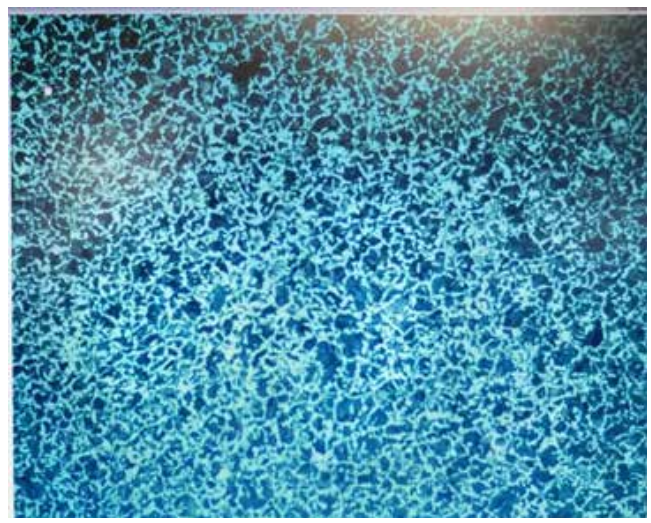

Figura 11: microestrutura do Aço 1045 laminado a quente

\section{Aquecimento}

Têmpera éo tratamento por resfriamento contínuo que promove a transformação da austenita em martensita. A amostra foi elevada até a temperatura de encharcamento de $900^{\circ} \mathrm{C}$ por um determinado tempo, esse tempo é calculado através da seguinte informação:

Para cada $1 \mathrm{~cm}$ de espessura equivale um tempo de aquecimento de $20 \mathrm{~min}$. Como a amostra tem $1.5 \mathrm{~cm}$ o tempo estimado para aquecimento foi de 30min (COLPAERTE, 2008).

Com o auxílio de um forno elétrico tipo mufla cada corpo de prova foi aquecido acima da temperatura de austenização que é de 
|Comportamento do processo de têmpera no aço sae 1045 através do resfriamento em óleo com viscosidades distintas

$900^{\circ} \mathrm{C}$ por 30 minutos como mostra a figura 12 .

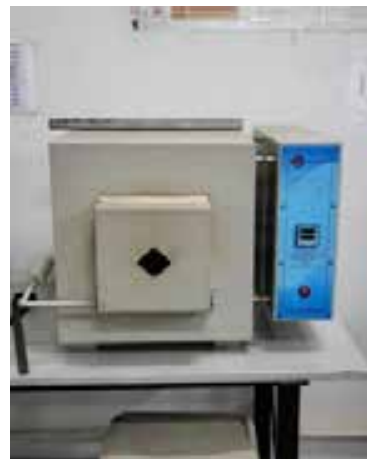

Figura 12: forno elétrico tipo mufla Resfriamento

É preciso que o volume do banho esteja em proporção com o tamanho da peça que se quer temperar, porque a capacidade de um líquido absorver calor diminui com a elevação da temperatura. Portanto, se o líquido for insuficiente ou se temperam várias peças com pequenos intervalos de tempo, no mesmo banho, o seu aquecimento excessivo pode produzir uma têmpera branda.

É importante também agitar a peça no banho durante a têmpera para assegurar um esfriamento mais uniforme. Os meios de resfriamento utilizados neste trabalho foram:

- Água

- Óleo 5W30

- Óleo 20w50

\section{Têmpera}

É importante salientar que todos os processos de preparação para observar a microestrutura realizados no item 3.1 serão repetidos para cada têmpera realizada.

Têmpera 1 - Resfriamento em água confirmou a estrutura de martensita, com formato característico de agulhas conforme mostra a figura 13.

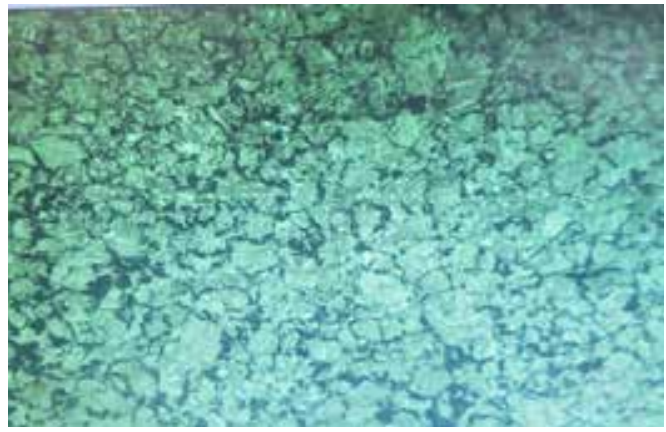

Figura 13: têmpera resfriada em água 
Têmpera 2 - Resfriamento em óleo 5w30 baixa viscosidade, podese observar uma têmpera moderada com formação de martensita e troostita, considerada uma têmpera branda. Conforme mostra a figura 14.

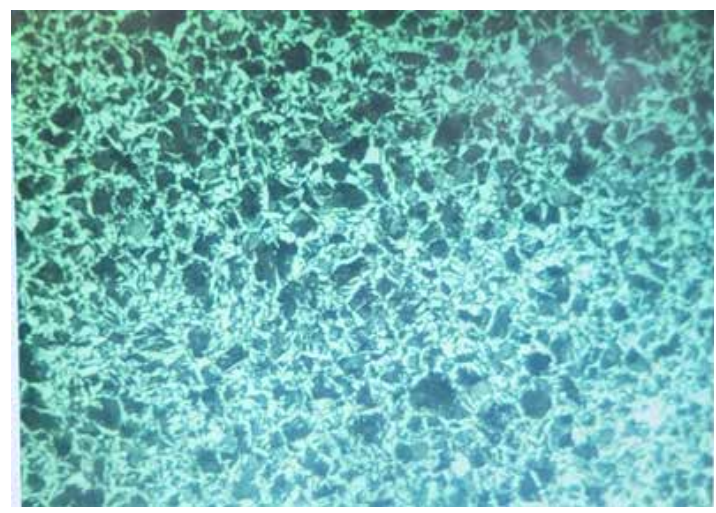

Figura 14: têmpera resfriada em óleo 5 w30

Têmpera 3 - Resfriamento em óleo SAE 20w50, média viscosidade. Constatou-se a formação de pequenas ilhas de martensita com troostopelita (troostita muito fina), considerada uma têmpera moderada. Como mostra a figura 15.

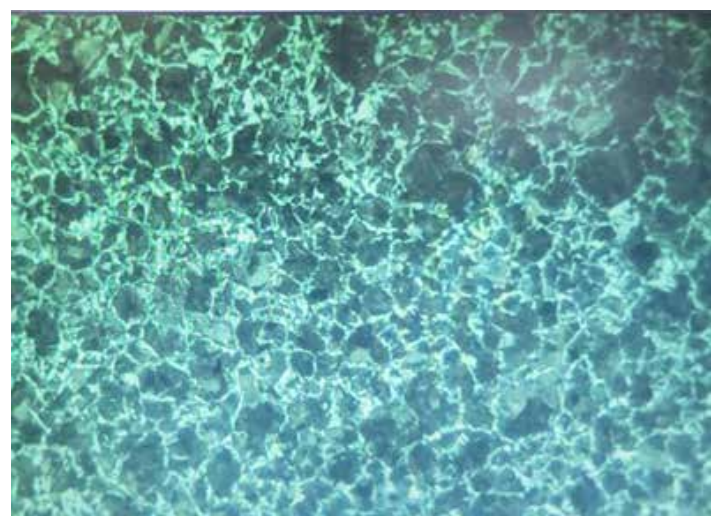

Figura 15: têmpera resfriada em óleo 20w50

Após o tratamento de têmpera de cada corpo de prova foi realizado então, o ensaio de dureza. Conforme listado abaixo:

Resfriamento em Água - 58 HRC (figura 16). 
|Comportamento do processo de têmpera no aço sae 1045 através do resfriamento em óleo com viscosidades distintas

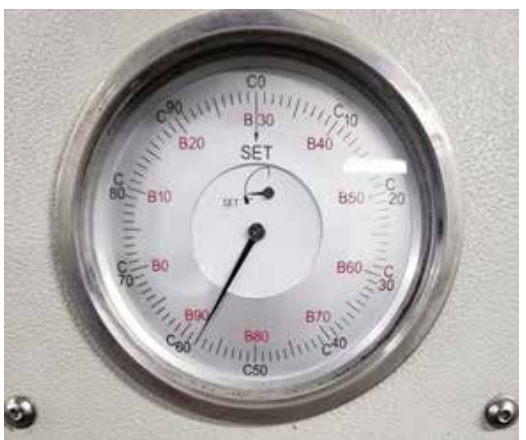

Figura 16: 58 HRC

Resfriamento em Óleo 5w30 - 17 HRC (figura 17).

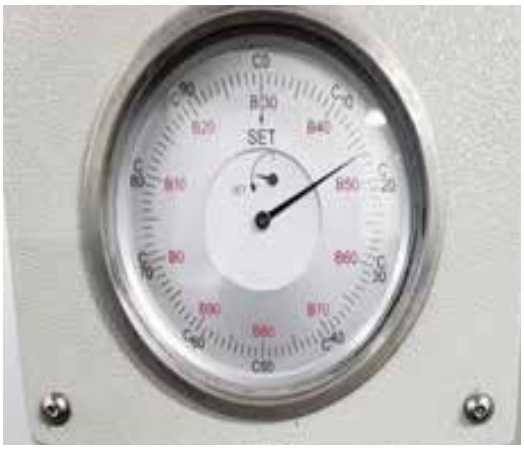

Figura 17: 17 HRC

Resfriamento em Óleo 20w50 - 10 HRC (figura 18).

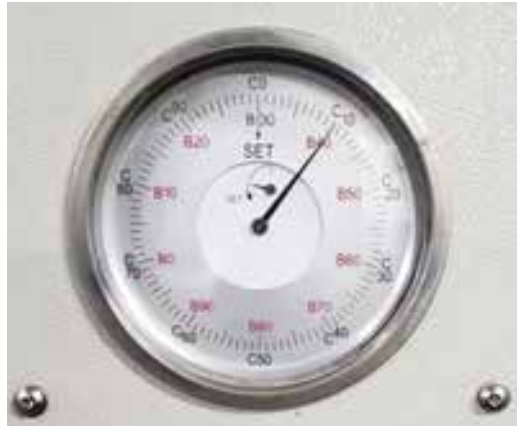

Figura 18: 10 HRC

O gráfico abaixo mostra a comparação das durezas com relação a têmpera em água, na qual, o resfriamento é visivelmente mais brusco denotando uma dureza maior. Medidas em HRC. 


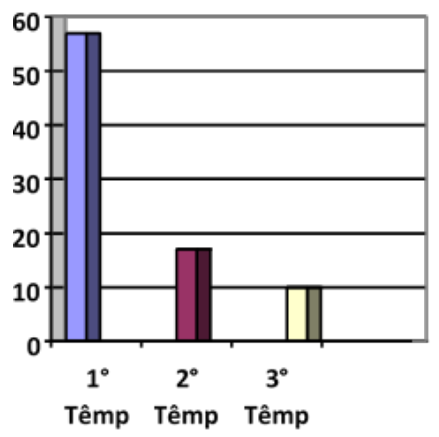

\section{Gráfico 1: comparação das durezas após a têmpera.}

\section{Conclusão}

De modo geral, há perda da propriedade magnética do aço em alta temperatura e a dureza é maior. O estudo realizado mostrou a comparação das microestruturas e das durezas e pode-se concluir que, quanto maior a viscosidade do óleo, menor será o tempo de resfriamento, ou seja, o resfriamento do material acontecerá de forma mais branda, ocasionando uma microestrutura com uma dureza menor que a da água, que é o que se busca. Quanto menor a dureza, o aço passa a ter uma maior flexibilidade e quebra com menos facilidade. Da Austenita, dependendo da velocidade do resfriamento, obtem-se Perlita para o resfriamento lento, Bainita para o moderado e Martensita para rápido.

Em relação às têmperas resfriadas em óleo, com o aumento da viscosidade a microestrutura final será composta por pequenas ilhas de martensita com troostoperlita.

Portanto, de acordo com as figuras apresentadas no trabalho as mudanças da estrutura cristalina de cada amostra podem ser observadas e conclui-se que quanto mais viscoso o óleo, menor a têmpera.

\section{Referências}

AÇOS E FERROS FUNDIDOS. Vicente Chiaverini. $7^{\circ}$ ED. Editora Associação Brasileira de Metais. 2012.

Artigo Científico - César Augusto CANCIAM Mestre em Engenharia Química. Departamento Acadêmico de Engenharia Química da Universidade Tecnológica Federal do Paraná - Câmpus Ponta Grossa. EFEITO DA TEMPERATURA NA VISCOSIDADE DINÂMICA DOS ÓLEOS LUBRIFICANTES SAE 5W20, SAE 5W30 E SAE 5W40.

METALOGRAFIA DOS PRODUTOS SIDERÚRGICOS COMUNS. $4^{\circ} \mathrm{Ed}$ Hubertus Colpaert. Instituto de pesquisas tecnológicas de São 
|Comportamento do processo de têmpera no aço sae 1045 através do resfriamento em óleo com viscosidades distintas

Paulo. 2008.

T. C. O. Nunes1, E. A. dos Santos 1, J. L. Pereira 2. 1 Instituto Federal de Educação, Ciência e Tecnologia do Pará - IFPA, Campus Belém, PA. 2 Agropalma, Tailândia, PA. ESTUDO COMPARATIVO DA VANTAGEM DE UMA TÊMPERA EM ÓLEO DE PALMA SOBRE A TÊMPERA TRADICIONAL EM AÇOS.

Tese Doutorado. Alessandro Fraga Farah. Universidade de São Paulo - USP, Ciência e Engenharia de Materiais - EESC, IFSC, IQSC. CARACTERIZAÇÃO DE ÓLEOS VEGETAIS COMO ALTERNATIVA PARA MEIOS DE RESFRIAMENTO UTILIZADOS NO TRATAMENTO TÉRMICO DE TÊMPERA. 